\title{
NUEVAS OPORTUNIDADES DE PARTICIPACIÓN EN EL MARCO DEL MODELO DE GOBIERNO ABIERTO $^{1}$
}

\author{
New Participation Opportunities within the framework of the \\ Open Government Model
}

\author{
María Dolores Montero Caro \\ Profesora Doctora del Área de Derecho Constitucional \\ Universidad de Córdoba \\ d22mocam@uco.es \\ https://orcid.org/0000-0001-9033-620X \\ http://dx.doi.org/10.18543/ed-68(1)-2020pp425-447
}

Recibido: 14.04 .2020

Aceptado: 12.06 .2020

\section{Resumen}

La sociedad de la información y la generalización del uso de internet han creado un nuevo modelo de sociedad totalmente incomparable a la de finales del s. XX. Nos encontramos en una sociedad en red globalizada que permanece informada de forma inmediata y que, a su vez, demanda un sistema de Gobierno Abierto basado en los pilares de transparencia, colaboración y participación. Precisamente, en lo referente a la participación, la ciudadanía nunca ha tenido tanta facilidad como la que ostenta ahora para poder expresarse a través de la web, redes sociales o aplicaciones móviles. $\mathrm{Si}$ bien es cierto que el modelo representativo sigue siendo el más adecuado a la

${ }^{1}$ Este estudio se trata de una extrapolación de algunas de las conclusiones obtenidas en la tesis doctoral de la propia autora, cuya defensa tuvo lugar el día 30 de enero de 2020. (Montero Caro, María Dolores. 2020. «El encaje constitucional del modelo de Open Government». Tesis doctoral. Universidad de Córdoba. https://helvia.uco.es/xmlui/handle/10396/19485) 
realidad social, política y jurídica de las democracias actuales, aún podría complementarse con nuevos mecanismos participativos.

\title{
Palabras clave
}

Gobierno abierto, participación ciudadana, democracia directa y democracia representativa.

\begin{abstract}
The information society and the generalization of the use of the Internet have created a new model of society totally incomparable to that of the end of the 20th century. We find ourselves in a globalised network society that is immediately informed and which, in turn, demands a system of Open Government based on the pillars of transparency, collaboration and participation. Precisely, in terms of participation, citizens have never had as much facility as they have now to express themselves through the web, social networks or mobile applications. Although it is true that the representative model continues to be the most appropriate for the social, political and legal reality of today's democracies, it could still be complemented by new participatory mechanisms.
\end{abstract}

\section{Key words}

Open Government, Citizen Participation, Direct Democracy and Representative Democracy. 
SUMARIO: I. LA PARTICIPACIÓN EN EL MODELO DEMOCRÁTICO ESPAÑL. 1. El referéndum. 2. La iniciativa legislativa popular. II. GoBIERNO ABIERTO Y PARTICIPACIÓN. 1. ¿Qué entendemos actualmente por Gobierno Abierto? 2. Iniciativas de éxito vinculadas al fomento de la participación ciudadana. 3. Iniciativas participativas frente a la pandemia provocada por el Coronavirus. III. CONSIDERACIONES FINALES. BIBLIOGRAFÍA.

\section{LA PARTICIPACIÓN EN EL MODELO DEMOCRÁTICO ESPAÑOL}

La democracia como forma de gobierno ha sido generalmente aceptada en los países europeos desde la segunda mitad del siglo XX, tras el fin de los regímenes totalitarios acontecidos en países como Italia, Alemania o la propia España ${ }^{2}$. Por esta razón, su posterior constitucionalización supuso, además de la definición de la forma de gobierno, su carácter como verdadero principio jurídico que, sustentado a su vez en los principios de igualdad y libertad, inspiraba al conjunto de poderes públicos.

En efecto, la democracia se entiende como una forma de gobierno donde el pueblo se configura como la única fuente de poder legítima. Dentro de este marco, el modelo de democracia más extendido en el mundo es el representativo, entre otras cuestiones, por tratarse de un sistema práctico que permite la cesión del poder popular en virtud de un mandato representativo libre.

Sin embargo, en la última década han sido numerosas las voces críticas al modelo actual de democracia representativa imperante en los países occidentales. Las razones esgrimidas por este sector crítico hacen alusión a la incapacidad de los gobernantes de gestionar la cosa pública, lo que conlleva irremediablemente a una pérdida de confianza política del electorado. Esta desconfianza se ve incrementada en períodos de crisis económica debido a las medidas drásticas adoptadas por los gobiernos que implican una reducción considerable de prestaciones y derechos.

Ya en el año 1969 se mencionaba la participación ciudadana como mecanismo capaz de producir reformas sociales de gran importancia. En este

2 Tanto el fascismo italiano personalizado en la figura de Benito Mussolini, Il Dulce; como el nacionalsocialismo de la Alemania de Adolf Hitler, el Führer; coinciden a grandes rasgos en las causas originarias del mismo: una crisis de carácter socioeconómico tras la Primera Guerra Mundial (paro, pobreza, etc), así como una crisis institucional y política que trajo aparejada un debilitamiento de los partidos e instituciones imperantes y un surgimiento de los partidos de masas. 
sentido, Arnstein (1969) introdujo la idea de la «escalera de participación ${ }^{3} »$ con diferentes grados en que puede presentarse, siendo considerados los peldaños más altos como una auténtica delegación del poder a la ciudadanía; y los más bajos, como mecanismos de mera manipulación pública sustitutivos de la verdadera participación.

Siguiendo la teoría de Arnstein, la verdadera participación que otorga poder de decisión real a la ciudadanía se configura como un instrumento de redistribución del poder, de tal forma que al comienzo del proceso político se eligen a aquellos que serán sus representantes, y al final de éste, exigirán un control de dicha gestión, es decir, una rendición de cuentas, término conocido como accountability en el mundo anglosajón.

Nuestra Constitución «diseña un sistema de participación política de los ciudadanos en el que priman los mecanismos de democracia representativa sobre los de participación directa» (STC 76/1994. FJ3). En la misma línea se ha manifestado el Tribunal Constitucional al entender que nos encontramos más bien en un tertium genus que llamado democracia participativa (STC 119/1995, de 17 de julio).

En España, los rasgos configuradores del sistema democrático son la soberanía popular, el pluralismo político y social y el reconocimiento de la participación política. Así, la soberanía popular consagrada en el artículo 1.2 CE reafirma al pueblo español como titular del poder constituyente, si bien, las Cortes Generales como representantes del pueblo conforman el poder constituido tras el ejercicio del derecho de sufragio.

No es el propósito de este estudio analizar con detalle cada uno de los instrumentos de participación directa existentes en nuestra Norma Suprema, pues ello daría lugar a un trabajo de investigación de otra naturaleza ${ }^{4}$. Por 4.

${ }^{3}$ Arnstein. Sherry. 1969. A Ladder of Citizen Participation. JAIP, volumen 35, núm.

${ }^{4}$ Existen numerosos estudios, y más en concreto Tesis Doctorales, que han profundizado de manera notable sobre los mecanismos de participación directa presentes en nuestra Constitución. Al respecto, podemos destacar los trabajos de Pérez Alberdi, quien hace un análisis exhaustivo del art. 23.1 CE, (Pérez Alberdi, María Reyes, 2010. «Participación política y derecho fundamental. El artículo 23.1 de la Constitución Española». Tesis doctoral. Universidad de Huelva) la tesis defendida por Alonso García, en la que deja constancia de la necesidad de nuevos mecanismos de participación directa en la sociedad democrática española actual (Alonso García, Nieves. 2018. «La integración de nuevas fórmulas de participación en la democracia representativa contemporánea». Tesis Doctoral. Universidad de León); o haciendo referencia a la necesidad de mayor democracia directa vinculada con la sociedad de la información, encontramos el trabajo de Abadía quien llega a la premisa de que a través de la e- Democracia se puede perfeccionar la representación, desarrollando para ello las estructuras ya existentes de democracia deliberativa y participativa (Abadía, Lorenzo. 2011 «Derechos políticos y sociedad de la información. 
este motivo, nos limitaremos a mencionar cuáles son estos mecanismos o instrumentos de democracia directa, partiendo de la base del derecho fundamental regulado en el art. $23 \mathrm{CE}$ donde, además de la participación por medio de representantes, se refiere al «derecho a participar en los asuntos públicos directamente...». Es en este punto donde nos planteamos la siguiente hipótesis: ¿son los mecanismos de participación directa suficientes para responder a la demanda ciudadana del s. XXI? Para intentar dar respuesta a esta pregunta es necesario, en primer lugar, hacer un breve recorrido en nuestra reciente historia democrática, para vislumbrar la eficacia de los dos mecanismos de participación directa más importantes, el referéndum y la iniciativa legislativa popular.

Cuando se habla de instrumentos de participación directa en sentido estricto la doctrina constitucional se detiene en analizar los dos más significativos: el referéndum, y la iniciativa legislativa popular. No obstante, existen otros instrumentos de participación presentes a lo largo del texto constitucional, véase, por ejemplo, la participación en la empresa (art. 129.2 $\mathrm{CE}$ ), el papel del Consejo Económico y Social (art. 131.2 CE), los Consejos de juventud (art. $48 \mathrm{CE}$ ), las organizaciones de consumidores y usuarios (art. $51.2 \mathrm{CE}$ ), etc. Igualmente, en el ámbito local, destaca, aunque con escasa aplicación práctica, el carácter asambleario de determinados municipios que funcionan en régimen de «concejo abierto» ${ }^{5}$ (art. $140 \mathrm{CE}$ ).

\section{El referéndum}

La Constitución de 1978 regula el referéndum en el art. 92, junto con el art. $167 \mathrm{CE}, 168 \mathrm{CE}$ y el recogido en el $151 \mathrm{CE}$, todos ellos desarrollados por la Ley Orgánica 2/1980, de 18 de enero, de Regulación de las Distintas Modalidades de Referéndum (LODMR, en adelante). Así, podemos distinguir en primer lugar, al referéndum sobre decisiones políticas de especial trascendencia. Esta es la modalidad contemplada en el art. $92 \mathrm{CE}$, la cual exige la convocatoria regia mediante la iniciativa del Presidente del Gobierno que, previamente ha debido ser autorizada por el Congreso de los Diputados por mayoría absoluta (art. 6 LODMR). Esta modalidad de referéndum

Elementos para un desarrollo de la democracia participativa». Tesis Doctoral. Universidad de Zaragoza)

${ }_{5}$ Sobre el régimen de concejo abierto aplicable a municipios con características particulares, en comparativa con el régimen común véase: Agudo Zamora, Miguel y Montero Caro, María Dolores. 2010. «El Modelo constitucional español de gobierno local», en Gobierno y democracia local: La experiencia andaluza y andina. Dir. Por. Castillo Blanco, F., Coord. por. Quesada Lumbreras, J.E., y Ramallo López, F.E. Unión Iberoamericana de Municipalistas, Granada. págs. 83-104. 
requiere que el mismo tenga carácter puramente consultivo, es decir, su resultado no es vinculante ni «es idóneo para perfeccionar actos o disposiciones de cualquier naturaleza, para los que será necesario, en su caso, una actuación posterior del poder público correspondiente» (Rodríguez Vergara, 2018, 552). Sin embargo, pese a tener un carácter meramente consultivo, «en la práctica resulta impensable que se adopte finalmente una decisión política en contra de lo expresado directamente por el cuerpo electoral» (Balaguer Callejón et al. 2018, 293)

Hasta la fecha, se han acometido dos referéndums de carácter consultivo en nuestro país. El primero de ellos, en 1986 cuando el Gobierno de entonces, presidido por Felipe González, preguntó a la ciudadanía sobre la permanencia de España en la OTAN, con la siguiente fórmula: «¿Considera conveniente para España permanecer en la Alianza Atlántica en los términos acordados por el Gobierno de la Nación?» siendo el resultado del sí mayor que el del no, pero con una estrecha diferencia (el 56,85\% frente al 43,15\% de los votos). Y, el segundo en el año 2005 sobre la ratificación del Tratado por el que se establecía una Constitución para Europa. En esta ocasión, la pregunta planteada fue: «¿Aprueba usted el Tratado por el que se establece una Constitución para Europa?», donde ganó el sí, con una mayoría contundente frente al no, pese a la escasa participación. No obstante, el no obtenido en Países Bajos y Francia supuso la no consumación final de la que pretendía erigirse como Constitución Europea.

En segundo lugar, encontramos el referéndum de ratificación de la reforma constitucional, que puede a su vez ser de dos tipos: con carácter facultativo cuando se trate de una reforma por el procedimiento ordinario y lo pida una décima parte de los miembros del Congreso o del Senado (art. 167.3 CE), o con carácter obligatorio cuando nos encontremos ante una reforma de las llamadas agravadas (art. 168.3 CE). En ambos casos, el resultado de la votación tendrá efectos vinculantes.

Asimismo, y relacionados con el Estado autonómico, nuestro texto constitucional enumera diferentes tipos de referéndums. Por un lado, encontramos los de la iniciativa para acceder a la autonomía por la vía del art. $151 \mathrm{CE}$, los de aprobación de los Estatutos de Autonomía de las Comunidades Autónomas que accedieron por la vía del art. $151 \mathrm{CE}$ (art. 151.2, y $3 \mathrm{CE}$ ) y, por último, los relativos a la reforma estatutaria de estos mismos Estatutos (art. 152.2 CE). No obstante, en la actualidad, podemos afirmar que de estas tres modalidades sólo la última, que hace referencia a la reforma estatutaria, estaría vigente, ya que el mapa autonómico se configuró en los primeros años de democracia, por lo que lo contenido en el art. $151 \mathrm{CE}$ se convierte en derecho transitorio ${ }^{6}$.

${ }^{6}$ Las Comunidades Autónomas que accedieron a la autonomía por la vía del art. 151 CE fueron: País Vasco, Cataluña, Galicia y, pese a la oposición inicial del gobierno nacio- 
En este punto se hace necesario resaltar que estas modalidades de referéndum previstas en la LODMR no agotan las posibilidades existentes en nuestro ordenamiento jurídico. En este sentido, el art. 149.1.32a $\mathrm{CE}$ reconoce la competencia exclusiva del Estado para autorizar la convocatoria de consultas populares. Este es el caso, por ejemplo, de las consultas populares incluidas en algunas de las reformas de los Estatutos de Autonomía y que han sido objeto de polémica, pues, en algunos casos, se ha extralimitado el concepto de «consulta popular» enmascarando un verdadero referéndum ${ }^{7}$. Igualmente, también se prevé la existencia de referéndums de ámbito local reconocidos en la Disposición Adicional octava de la LODMR y recogidos en la Ley Reguladora de Bases del Régimen Local (LBRL, en adelante) otorgando al alcalde o alcaldesa, previo acuerdo del Pleno de ayuntamiento y autorización del Gobierno de la Nación, la iniciativa de someter a consultas populares asuntos municipales y locales de especial relevancia para los vecinos de dicho territorio (art. $71 \mathrm{LBRL}$ ).

Otro de los debates recurrentes en torno a las distintas modalidades de referéndum existentes en nuestro modelo constitucional es el que hace referencia a la no regulación de las consultas abrogativas. Dicha modalidad se llegó a plantear en el anteproyecto de nuestra Constitución ${ }^{8}$ y está vigente en algunos países de nuestro entorno, como Francia, Austria, Italia o Irlanda9,

nal de aquel momento, presidido por Adolfo Suárez, también Andalucía. Por ello, las reformas estatutarias acometidas en la primera década del s.XXI por estas CCAA han sido objeto de referéndum entre su población.

7 STC 103/2008 que declara inconstitucional la Ley 9/2008, de 27 de junio, de convocatoria y regulación de una consulta popular al objeto de recabar la opinión ciudadana en la Comunidad Autónoma del País Vasco sobre la apertura de un proceso de negociación para alcanzar la paz y la normalización política, y STC 31/2015 que declara la inconstitucionalidad de diversos preceptos de la Ley Catalana 10/2014, de 26 de septiembre, de consultas populares no refrendarias y otras formas de participación ciudadana.

${ }^{8}$ El art. 85 del Anteproyecto de CE establecía que: «1. La aprobación de las leyes votadas por las Cortes Generales y aún no sancionadas, las decisiones políticas de especial trascendencia y la derogación de leyes en vigor, podrán ser sometidas a referéndum de todos los ciudadanos. 2. En los dos primeros supuestos del número anterior el referéndum será convocado por el Rey, a propuesta del Gobierno, a iniciativa de cualquiera de las Cámaras, o de tres asambleas de territorios autonómicos. En el tercer supuesto, la iniciativa podrá proceder también de setecientos cincuenta mil electores. 3. El plazo previsto en el artículo anterior, para la sanción real, se contarán en este supuesto, a partir de la publicación oficial del resultado del referéndum. 4. El resultado del referéndum se impone a todos los ciudadanos y a todos los órganos del Estado. 5. Una ley orgánica regulará las condiciones del referéndum legislativo y del constitucional, así como la iniciativa popular a que se refiere el presente artículo y la establecida en el art. 80».

${ }^{9}$ El art. 11 de la Constitución francesa de 1958 establece que «El Presidente de la República, a propuesta del Gobierno y mientras dure el período de sesiones, o a propues- 
entre otros. Se entiende, por tanto, que el constituyente español retrocedió en la inclusión de lo que podría haber sido un mecanismo más de democracia participativa en pro de un mayor peso del papel de los partidos. Uno de los defensores que ha abordado más recientemente la necesidad de una reforma constitucional que permita la inclusión del referéndum abrogatorio en nuestro país ha sido Gabriele Vestri $(2017,99)$, quien se ha atrevido a dar una posible redacción constitucional:

\section{«1. Se reconoce el derecho de participación política a través de refe- rendo popular.}

ta conjunta de las dos Cámaras, publicadas en el Journal Officiel (Boletín Oficial), podrá someter a referéndum cualquier proyecto de ley que verse sobre la organización de los poderes públicos, sobre reformas relativas a la política económica o social de la Nación y a los servicios públicos que concurren en ella, o que proponga la ratificación de un tratado que, sin ser contrario a la Constitución, pudiera tener incidencias en el funcionamiento de las instituciones. Cuando se organice el referéndum a propuesta del Gobierno, éste presentará ante cada Cámara una declaración que será seguida de un debate. Cuando el referéndum concluya con la aprobación del proyecto de ley, el Presidente de la República promulgará la ley dentro de los quince días siguientes a la proclamación de los resultados de la consulta».

Por su parte, el art. 43 de la Constitución Austriaca de 1920 prevé: «Toda resolución legislativa del Consejo Nacional deberá ser sometida a votación popular (Volksabstimmung) una vez finalizado el procedimiento según el artículo 42, pero siempre antes de su promulgación por el Presidente federal, si lo acuerda así el propio Consejo Nacional o lo pide la mayoría de los miembros del mismo».

En Italia, el art. 75 de la Constitución de 1947 dispone que «Se celebrará referéndum popular para decidir sobre la derogación total o parcial de una ley o de un acto con fuerza de ley cuando lo soliciten 500.000 (quinientos mil) electores o cinco consejos regionales. No se admitirá el referéndum para las leyes tributarias y presupuestarias, de amnistía y de indulto, ni de autorización para ratificar tratados internacionales. Tendrán derecho a participar en el referéndum todos los ciudadanos llamados a elegir la Cámara de Diputados. La propuesta sometida a referéndum será aprobada si ha participado en la votación la mayoría de quienes tengan derecho a hacerlo y si se alcanza la mayoría de los votos validamente emitidos. La ley determinará las modalidades de celebración del referéndum»

Igualmente en Irlanda, la regulación de esta modalidad de referéndum aparece reflejada en el art. 27 de la Constitución de 1937: «El presente artículo será aplicable a cualquier proyecto de ley que, no conteniendo declaradamente una propuesta de modificación de esta Constitución, se considere, en virtud del artículo 23 de esta, como aprobado por las dos Cámaras del Parlamento. Podrán la mayoría de los componentes del Senado y no menos de un tercio de los miembros de la Cámara de Representantes, mediante petición conjunta dirigida al Presidente de la República con arreglo al presente artículo, solicitar al Presidente que se abstenga de firmar y promulgar como ley un proyecto determinado al que sea aplicable este artículo, por la razón de que el proyecto contiene alguna propuesta de tal importancia que se debería comprobar cuál es la voluntad del pueblo sobre el particular». 
2. El referendo popular, solicitado por al menos un millón de electores y electoras representativos de los territorios autonómicos, podrá derogar total o parcialmente una ley o un acto con fuerza de ley.

3. Tendrán derecho a participar en el referendo todos los ciudadanos que gocen de los derechos civiles y politicos.

4. La propuesta deberá ser aprobada si ha participado en la votación la mayoría de quien tenga derecho al voto y si se alcanza la mayoría de los votos válidamente emitidos.

5. La decisión que proceda del referendo será vinculante.

6. Se prohibe el referendo en materias propias de ley orgánica, tributarias, referente a la unidad de España y en lo relativo a la prerrogativa de gracia.

7. Una ley orgánica regulará las condiciones para celebrar el referendo»

\section{La Iniciativa Legislativa Popular}

Sobre la iniciativa legislativa popular (ILP, en adelante) se pronuncia el art. 87.3 CE, como un mecanismo ulterior de activación del procedimiento legislativo, que se suma a las previstas para el Gobierno, el Congreso, el Senado y las Asambleas de las CCAA. En el supuesto de la ILP, desarrollada por la Ley Orgánica 3/1984, de 26 de marzo, reguladora de la iniciativa legislativa popular (LOILP, en adelante), nuestra Constitución contempla la obligatoriedad de alcanzar un mínimo de 500.000 firmas acreditadas y limita su uso respecto a materias propias de ley orgánica, tributarias o de carácter internacional o, incluso, en todo lo referente a la prerrogativa de gracia.

La historia democrática de nuestro país muestra un carácter meramente anecdótico de la efectividad de este procedimiento. Ejemplo de ello es el escaso uso que se hace de este mecanismo, siendo pocas las ILP presentadas en los más de 40 años de vigencia de nuestra Carta Magna y, menos aún aquéllas que, presentadas, han logrado convertirse en ley o modificar alguna ya existente.

Haciendo una comparativa del número de ILP presentadas en nuestro país entre 1983 y abril de 2020 se puede comprobar claramente la ineficacia de su existencia. En síntesis, de las 110 ILP presentadas hasta la fecha de redacción de este estudio (118 si tuviéramos en cuenta las que actualmente se encuentran pendientes de resolución), 45 de ellas fueron directamente inadmitidas a trámite por la Mesa del Congreso. De las admitidas, 44 caducaron al no alcanzar las 500.000 firmas en el plazo establecido por la LOILP ${ }^{10}$ y otras 6

${ }^{10} \mathrm{El}$ art. 7.3 de la LOILP, modificado por el apartado cuarto del artículo único de la L.O. 4/2006, de 26 de mayo, de modificación de la L.O. 3/1984, de 26 de marzo, regula- 
decaídas o retiradas finalmente por sus promotores. De este modo, sólo 13 ILP han alcanzado la fase de trámite parlamentario, llegando sólo tres a convertirse en ley. En primer lugar, la proposición de ley sobre reclamación de deudas comunitarias que fue subsumida con otras dos proposiciones parlamentarias dando lugar finalmente a la aprobación de la Ley 8/1999, de 6 de abril, de reforma de la Ley sobre Propiedad Horizontal. En segundo lugar, la proposición de ley para la regulación de la tauromaquia como patrimonio cultural culminó con la aprobación de la Ley 18/2013, de 12 de noviembre, para la regulación de la tauromaquia como patrimonio cultural. Y en tercer y último lugar, la proposición de ley de regulación de la dación en pago, de paralización de los desahucios y de alquiler social quedó también subsumida en la proposición de ley de medidas para reforzar la protección a los deudores hipotecarios, reestructuración de deuda y alquiler social, que culminó con la aprobación de la Ley 1/2013, de 14 de mayo, de medidas para reforzar la protección a los deudores hipotecarios, reestructuración de deuda y alquiler social.

Pese a la escasa probabilidad de éxito de una ILP (entendiendo como éxito que llegue a plasmarse en la aprobación o modificación de una ley), el TC se pronunció de la siguiente forma en la STC 124/1995: "con independencia, por tanto, de que la propuesta prospere ante el Pleno, la función principal de este cauce de participación se habrá conseguido haciendo posible que los ciudadanos puedan conocer lo que sus representantes piensan sobre una determinada materia, así como sobre la oportunidad o no de su regulación legal, y extraer sus propias conclusiones acerca de cómo aquéllos asumen o se separan de lo manifestado en sus respectivos programas electorales».

Igualmente, cada Comunidad Autónoma prevé un mecanismo de iniciativa legislativa popular propio ${ }^{11}$ con un requerimiento en cuanto al número de firmas proporcional a su población. Por citar un ejemplo peculiar, y a diferencia de la única ILP que ha prosperado convertida en ley a nivel nacional, la referente a la protección de la tauromaquia, encontramos la admisión a trámite y debate parlamentario de la ILP que dio lugar a la Ley

dora de la Iniciativa Legislativa Popular establece que: «El procedimiento de recogida de firmas deberá finalizar con la entrega a la Junta Electoral Central de las firmas recogidas, en el plazo de nueve meses a contar desde la notificación a que se refiere el apartado anterior. Este plazo podrá ser prorrogado por tres meses cuando concurra una causa mayor apreciada por la Mesa del Congreso. Agotado el plazo sin que se haya hecho entrega de las firmas recogidas, caducará la iniciativa»

${ }^{11}$ Para un estudio en profundidad de las iniciativas legislativas populares en el ámbito autonómico véase: Cabedo Mallol, Vicente José. 2009. «La iniciativa legislativa popular en las Comunidades Autónomas. La necesaria reforma de su legislación», en Teoría y Realidad Constitucional, núm. 24, págs. 455-476. 
28/2010, de 3 de agosto, que, en este supuesto, prohibió las corridas de toros en Cataluña ${ }^{12}$.

Sin embargo, en lo que atañe a la iniciativa legislativa popular en el ámbito autonómico también debemos hacer una crítica constructiva que nos lleve a preguntarnos por qué en la práctica no es un mecanismo de participación directa o, mejor dicho, semidirecta eficaz. Parte de la culpa de esta ineficacia se debe al desarrollo normativo de estas ILP autonómicas, puesto que, tal y como afirma Cabedo Mallol $(2009,475)$, «desgraciadamente, las leyes reguladoras de la iniciativa legislativa popular no han favorecido esta participación ciudadana en el ámbito legislativo, como lo demuestra el escaso número de iniciativas populares presentadas $\mathrm{y}$, fundamentalmente, porque pocas de ellas logran su objetivo: convertirse en ley.»

Por último, se hace necesario resaltar la importancia que está adquiriendo a nivel europeo la conocida como Iniciativa Ciudadana Europea (ICE, en adelante). Se trata éste de un procedimiento homólogo a la ILP nacional, pero que engloba esta vez a los ciudadanos europeos como sujetos capaces de participar activamente en el procedimiento legislativo. Para ello, podrán dirigirse directamente a la Comisión e instar a presentar una propuesta de acto legislativo de la Unión. La finalidad de esta nueva figura contemplada en el art. 11.4 del Tratado de la Unión Europea y desarrollada por el Reglamento (UE) núm. 211/2011 del Parlamento Europeo y del Consejo, de 16 de febrero de 2011 y del Reglamento de Ejecución (UE) núm. 179/2011 de la Comisión, de 17 de noviembre de 2011 es la de otorgar un derecho de participación en el poder legislativo a todos los ciudadanos de la Unión, favoreciendo así el carácter democrático de la construcción europea a diferencia de sus primeros años, durante los cuales se centraba más en el carácter económico como base del establecimiento de un mercado común.

Para garantizar el carácter europeo de esta iniciativa se exige que la misma provenga de un comité organizador compuesto por siete o más ciudadanos que tengan edad suficiente para votar en las elecciones al Parlamento Europeo y que residan en, al menos, siete Estados miembros distintos. Una vez confirmada la inscripción de la ICE, los organizadores dispondrán de un plazo máximo de 12 meses para recoger un mínimo de un millón de

${ }^{12}$ Esta Ley que dio como resultado la abolición de la celebración de corridas de toros en la Comunidad Autónoma de Cataluña fue recurrida por el Partido Popular, siendo estimada por el Tribunal Constitucional mediante la STC 177/2016. Para un análisis en profundidad de las consecuencias de esta sentencia véase: Mulà Arribas, Anna. 2018. «Análisis jurídico, antecedentes y consecuencias de la Sentencia 177/2016, del Tribunal Constitucional, sobre prohibición de las corridas de toros en Cataluña» en RDUNED: Revista de Derecho UNED, núm. 22, págs. 407-436. 
declaraciones de apoyo electrónicas o en papel (equivalente al sistema de recogida de firmas en el caso de la ILP nacional).

Una vez examinada la iniciativa por la Comisión, en el plazo de tres meses, ésta se reunirá con los organizadores, quienes, a su vez, podrán presentar su iniciativa en audiencia pública ante el Parlamento Europeo. Posteriormente, la Comisión aprobará en documento oficial si propone o no medidas en respuesta a la ICE, explicando los motivos que le hayan llevado a dicha decisión. Si el resultado fuera la aprobación de una nueva norma, ésta se deberá llevar a cabo por el procedimiento legislativo habitual, aunque, en ningún caso, la Comisión quedará vinculada por su contenido.

En el momento de la fecha de redacción de este estudio, abril de 2020, son cinco las ICE que han prosperado, de las 72 registradas. Alguna de ellas se encuentra actualmente abierta y en fase de recogida de declaraciones de apoyo, por lo que el número final de ICE que lleguen a término con éxito puede verse aumentado en un breve plazo de tiempo.

La incorporación de la ICE ha favorecido el concepto de identidad europea como sujeto de derechos políticos y sociales, más allá del ámbito económico de la integración europea. De ahí que se alegue que «la ICE, pueda considerarse un importante instrumento para la democratización de Europa que trate de salvar la distancia existente entre las instituciones y los ciudadanos europeos. De ahí que su implementación pueda mejorar la integración de Europa desde abajo, desplegando todo su potencial creador de comunidad» (Burguera Ameave 2015, 272).

\section{GOBIERNO ABIERTO Y PARTICIPACIÓN}

\section{1. ¿Qué entendemos actualmente por Gobierno Abierto?}

En los últimos años, la generalización de una sociedad globalizada e interconectada, una «sociedad red» ${ }^{13}$ como la define Manuel Castells (2006), viene reclamando un nuevo sistema de gobierno que perfeccione nuestra democracia. La solución no radica en romper con el consolidado sistema representativo, sino en buscar mecanismos e instrumentos de participación popular que permitan la convivencia con él. Precisamente, las nuevas tecnologías de la información y comunicación y, en particular, la aparición y extensión de internet, han cambiado sustancialmente la forma de los ciudadanos de relacionarse y comunicarse. Pese a que existen corrientes contrarias a

${ }_{13}$ Para un análisis en profundidad sobre la idea de «sociedad red» véase: Castells, Manuel. 2006. La Sociedad Red. Alianza Editorial y Castells, Manuel. 2012. Redes de indignación y esperanza. Alianza Editorial, Madrid. 
la apertura de nuevas vías de participación directa al entender que las mismas desvirtuarían el propio principio de representatividad, la realidad nos muestra que probablemente no exista un mayor daño que el de no garantizar medidas que conlleven la efectividad de dicha representación durante todo el período del mandato público.

Es en este punto precisamente donde podemos introducir las ventajas que permite la implantación del nuevo modelo de Gobierno Abierto, cuyo precedente se encuentra en el ámbito anglosajón en el siglo XX con las conocidas como Freedom of Information Acts, o leyes de libertad de información ${ }^{14}$. Sin embargo, existe unanimidad en datar a principios de 2009 el origen del concepto actual de Gobierno Abierto, coincidiendo con la redacción del recién elegido presidente estadounidense Barack Obama del Memorándum sobre Transparencia y Gobierno Abierto ${ }^{15}$, en el que quedaron reflejados por vez primera los tres pilares básicos del mismo: transparencia, participación y colaboración.

La apuesta clara por el uso de las nuevas tecnologías y las redes sociales durante la campaña electoral de 2008 del aún candidato Barack Obama (aspecto éste que resultó determinante en su victoria) ya hacía presagiar el alto compromiso que la nueva administración tendría con una mayor apertura del gobierno con la ciudadanía, que repercutiera también en la mejora de la actividad gubernamental.

Así pues, desde finales del primer decenio del siglo XXI ya nadie duda de que los cambios en el modelo social son evidentes. De hecho, la aparición de internet ha favorecido un nuevo modelo de participación en el que prima el individuo como sujeto de intereses propios, pues, hasta hace relativamente poco tiempo, hablar de participación significaba hablar de participación colectiva a través de grupos, clases o asociaciones, quienes eran finalmente los que canalizaban los intereses de sus integrantes, diluyendo así la participación individual.

En la actualidad coexisten ambos modelos de participación ciudadana; por un lado, la realizada a través de los grupos en los que se integra el individuo (asociaciones de consumidores y usuarios, de estudiantes, sindicatos, ONG, etc.) y que comparten unos intereses comunes; y por otro lado, la participación individual que empodera al propio ciudadano permitiéndole dar su

${ }^{14}$ Un estudio pormenorizado de la FOIA de 2000 en Reino Unido la encontramos en: Birkinshaw, P., 2010. «Freedom of information and its impact in the United Kingdom», en Government Information Quarterly, Vol. 27, Issue 4, págs. 312-321. Igualmente, para un breve pero interesante análisis de la FOIA de Estados Unidos, véase: Relyea H.C., 2009. «Federal freedom of information policy: highlights of recent developments», en Government Information Quarterly, Vol. 26, Issue 2, págs. 314-320.

15 Obama, Barack. 2009. «Transparency and Open Government Memorandum for the heads of executive departments and agencies» en Federal Register, núm. 74-15, págs. 4685-4686. 
opinión sobre un tema de interés público de forma rápida y sencilla a través de la pantalla de su ordenador o de su smartphone.

La crisis de institucional y de representación española hace necesario revisar las reglas del juego de los instrumentos de democracia participativa existentes en nuestro ordenamiento jurídico con el objetivo de dar mayor protagonismo a las fórmulas de participación política y social directas, sin que ello suponga la pérdida de la esencia de nuestra democracia representativa. Aunque esta situación pudiera parecer novedosa, ya en 1920 Kelsen hacía alusión a este tipo de desafección política e institucional a través de lo que él llamó «cierta fatiga del parlamentarismo», ${ }^{16}$ deseoso de un fortalecimiento democrático.

Siguiendo las razones esgrimidas por Presno Linera (2015, 137-162), podemos decir que gran culpa de esta desafección ciudadana ante sus representantes e instituciones en España se debe a circunstancias tales como: la cuestionada proporcionalidad que presenta nuestro sistema electoral, ${ }^{17}$ la colocación de los intereses de los partidos políticos en sede parlamentaria por encima de los intereses del representante de forma individual, el escaso uso de la cuestión de confianza para comprobar el respaldo parlamentario del gobierno ante una decisión de gran trascendencia sobre su programa de gobierno o sobre una cuestión de política general (art. $112 \mathrm{CE}$ ), así como la ausencia de participación ciudadana en el debate legislativo parlamentario.

\section{Iniciativas de éxito vinculadas al fomento de la participación ciudadana}

Si algo hemos aprendido en los últimos años es que una idea generalizada por parte de la población de falta de representatividad da lugar a un sentimiento de desilusión que puede, en el peor de los casos, provocar una desvinculación de las políticas democráticas, abonando así el terreno para el auge de partidos o movimientos populistas.

\section{5.}

${ }^{16}$ Kelsen, Hans. 2006. De la esencia y valor de la democracia, KKK, Oviedo, pág.

${ }^{17}$ El Consejo de Estado se pronunció al respecto de una posible reforma electoral en los siguientes términos «que el sistema electoral del Congreso de los Diputados [...]presenta algunos aspectos que podrían ser susceptibles de mejora, en aras de garantizar la igualdad de electores y partidos políticos en el proceso electoral y de revalorizar la participación de los ciudadanos en la designación de sus representantes [...] un avance en este sentido podría comportar efectos beneficiosos para el fomento de la participación política de los ciudadanos y una mayor implicación de éstos en el funcionamiento democrático de las instituciones, en línea con lo ya dispuesto en la inmensa mayoría de los ordenamientos europeos». Este informe del Consejo de Estado aprobado en 2009 se puede consultar en su totalidad en: http://www.consejo-estado.es/pdf/REGIMEN-ELECTORAL.PDF (Fecha de consulta: septiembre 2019) 
Han sido numerosas las iniciativas de Gobierno Abierto adoptadas por los países que componen la Alianza para el Gobierno Abierto ${ }^{18}$ (OPG, Open Government Partnetship, por sus siglas en inglés) desde su creación en el año 2011. No obstante, como ejemplos pioneros y de referencia para el resto de territorios, nos detendremos a analizar dos iniciativas de fomento de participación pública: «we the people» $\mathrm{y}$ «e-petitions», creadas en Estados Unidos y en Reino Unido respectivamente.

«We the people», creada en septiembre de 2011, se acabó pronto convirtiendo en una de las iniciativas más populares introducidas por la Administración Obama. A través de ella, los usuarios, previamente registrados, proponían una petición online y, si era posible, la relacionaban con otras activas similares, recibiendo respuesta oficial por parte de la Casa Blanca si dicha petición alcanzaba un apoyo de, al menos, cien mil firmas en treinta días. Fueron importantes los casos de éxito de esta iniciativa, llegando en algunos supuestos a producir verdaderas reformas normativas (ley de aseguramiento al consumidor para usar sus dispositivos móviles en la red de su elección) o pronunciamientos públicos (manifiesto del Presidente de apoyo a la prohibición de terapias de conversión en menores transexuales).

Con la llegada de Donald Trump a la Casa Blanca, esta iniciativa de participación ciudadana quedó en suspenso e, incluso, fueron numerosas las voces que daban por hecho su finalización, puesto que, justo tras su toma de posesión, el nuevo gobierno desactivó todas las peticiones que se encontraban en curso. No obstante, aunque hubo que esperar hasta marzo de 2018, el Gobierno comenzó a responder a algunas de estas peticiones.

«E- petitions», salvando las distancias, podría considerarse la homónima británica de «we the people». Así pues, se trata también de una herramienta online que permite a los ciudadanos británicos o residentes crear una petición sobre un asunto público. Para ello, será necesario contar con otras cinco personas que apoyen la petición lanzada por un ciudadano, en cuyo caso será posteriormente publicada en la web creada al efecto (www.petions.parliament.uk). Posteriormente, la Comisión de Peticiones (Petitions Committee) seleccionará aquellas que considere de gran interés y podrá solicitar más información a los proponentes. Cabe destacar que esta Comisión dispone del poder para presionar al Parlamento británico o al Gobierno para que actúe. Finalmente, si la petición alcanza la cifra de 10.000 firmas de apoyo, el

${ }_{18}$ Se trata de una red internacional cuya misión principal es la de conseguir que los gobiernos sean más transparentes, rindan cuentas y mejoren la capacidad de respuesta hacia sus ciudadanos con el objetivo final de mejorar la calidad del gobierno y de los servicios que reciben. Para conocer de forma actualizada cada uno de los Planes de Acción elaborados por los diferentes países que componen la OGP puede consultarse en su web: https://www.opengovpartnership.org 
Gobierno está obligado a responderla. Pero, si logra superar las 100.000 firmas, la petición podrá ser debatida en el Parlamento.

En este punto, resulta cuanto menos curioso comprobar cómo desde la aprobación del Brexit tras el referéndum del 23 de junio de $2016^{19}$, un gran porcentaje de las peticiones realizadas por la ciudadanía británica a través de la plataforma e-petitions versan sobre esta cuestión. De hecho, desde entonces, la petición ciudadana debatida en el Parlamento británico que ha obtenido mayor número de firmas (más de seis millones, cifra ésta muy por encima de la segunda más apoyada, la cual no llega a 600 mil firmas) es la titulada como: «Revocación del artículo 50 y permanencia en la UE» (Revoke Article 50 and remain in the EU). Esta petición, al alcanzar con creces el número de 10 mil firmas, tuvo que ser en un primer lugar respondida por el Gobierno británico, quien claramente dejó clara su postura en su respuesta:

"This Government will not revoke Article 50. We will honour the result of the 2016 referendum and work with Parliament to deliver a deal that ensures we leave the European Union ${ }^{20} 》$ («Este Gobierno no revocará el artículo 50. Honraremos el resultado del referéndum de 2016 y trabajaremos con el Parlamento para alcanzar un acuerdo que garantice que abandonamos la Unión Europea»)

Iniciativas como «we the people» en Estados Unidos y «e-petitions» en Reino Unido han contribuido al fomento de la mentalidad cívica y social en asuntos políticos o de interés público en general. Sin embargo, «la elevada demanda de peticiones surgidas en los últimos años lleva a plantearse nuevos retos como son: dar respuesta a todas ellas, distinguir lo que es adecuado de lo que es popular, así como el gran reto de gestionar las expectativas creadas por la opinión pública» (Leston-Bandeira y Thompson 2018, 350).

Si bien es cierto que los mecanismos de participación directa existentes en nuestro modelo constitucional son insuficientes, también es cierto que a nivel autonómico y, sobre todo, a nivel local son muchas las iniciativas que se han impulsado con gran éxito de participación entre la ciudadanía. Es evidente que

19 Para una información detallada sobre lo que ha supuesto el apoyo del Brexit (Britain Exit) tanto para Reino Unido como para el conjunto de la UE véase: Serrano Sanz, José María. 2016. «La economía y el Brexit», en El Cronista del Estado Social y Democrático de Derecho, Núm. 64, págs. 18-21; Sarmiento, Daniel. 2016. «y después del Brexit... ¿Qué?», en El Cronista del Estado Social y Democrático de Derecho, Núm. 64, págs. 42-47; y Pereira Menaut, Antonio Carlos. 2016. «Para entender el Brexit», en Diario La Ley, Núm. 8812.

${ }^{20}$ Tanto la respuesta a la petición ciudadana sobre la derogación del art. 50 y la vuelta a la UE como su posterior debate parlamentario (marzo y abril de 2019 respectivamente), se puede consultar en: https://petition.parliament.uk/petitions/241584\#debate-threshold (Fecha de consulta: noviembre 2019) 
la participación pública tiene más recorrido en aquellos niveles territoriales más cercanos a la ciudadanía, ya que se ocupa de asuntos cotidianos que les afecta en mayor medida en su vida diaria (presupuestos locales, centros de salud, educación, polideportivos, parques, alumbrado, etc.) Citando algún ejemplo municipal, uno de los más mediáticos y con mayor éxito de los últimos años lo encontramos en la iniciativa «Decide Madrid ${ }^{21}$. Con esta herramienta, cualquier ciudadano (extensible también a los extranjeros) puede hacer una propuesta de mejora de la ciudad, así como votar en los asuntos planteados por el propio Gobierno municipal que requiera del apoyo o no de la ciudadanía. En lo referente a las propuestas ciudadanas, es necesario que la misma consiga el apoyo del $1 \%$ de personas mayores de 16 años empadronadas en Madrid, en cuyo caso pasará a una segunda fase de votación. Una vez obtenido ese apoyo, se abrirá un período de votación pública y, si se consiguen más votos a favor que en contra, el Consistorio asumirá la propuesta y la llevará a cabo. Algunos de los ejemplos de propuestas ciudadanas aprobadas por esta vía han sido: Madrid 100\% sostenible y Billete único para el transporte público.

\section{Iniciativas participativas frente a la pandemia provocada por el Coronavirus}

Todo lo hasta ahora expuesto da un giro de 180 grados a partir del 11 de marzo de 2020, momento en el cual la Organización Mundial de la Salud (OMS) eleva de situación de emergencia para la salud pública ocasionada por el nuevo coronavirus (COVID-19) a pandemia internacional ${ }^{22}$. Desde entonces, la mayor parte de los gobiernos han dejado al margen su agenda ordinaria para centrarse en combatir la propagación de este virus.

España, de forma desgraciadamente vertiginosa, pasó a ser uno de los países con más casos de infectados del mundo a mediados y finales de marzo (sólo por detrás de China e Italia). Ante esta evolución de los acontecimientos, el Gobierno decretó el 14 de marzo de 2020 el estado de alarma en todo el territorio nacional durante un período de 15 días, que ha sido objeto de diferentes prórrogas por el mismo período ${ }^{23}$. (Real Decreto 463/2020, de 14

${ }^{21}$ Se puede acceder al portal «Decide Madrid» a través de la web: https://decide.madrid.es

${ }^{22}$ El 31 de diciembre de 2019, China notifica una aglomeración de casos de neumonía en Wuhan y determina que están causados por un nuevo coronavirus. Los impresionantes niveles de propagación de la enfermedad, así como su gravedad y los niveles también alarmantes de inacción, obliga a la OMS, el 11 de marzo de 2020, a evaluar el COVID-19 como pandemia.

${ }^{23}$ La primera prórroga del estado de alarma la encontramos en: Real Decreto $476 / 2020$, de 27 de marzo, por el que se prorroga el estado de alarma declarado por el Real Decreto 463/2020, de 14 de marzo, por el que se declara el estado de alarma para la ges- 
de marzo, por el que se declara el estado de alarma para la gestión de la situación de crisis sanitaria ocasionada por el COVID-19) ${ }^{24}$. La facultad que habilita al Ejecutivo para decretar esta situación excepcional se encuentra prevista en el art. 116 CE y desarrollado por la Ley Orgánica 4/1981, de 1 de junio, de los estados de alarma, excepción y sitio.

Todos los países que forman parte de la Alianza para el Gobierno Abierto tienen la obligación de elaborar los llamados «Planes de Acción de Gobierno Abierto», que deben actualizarse cada tres años. En ellos deben constar los compromisos adquiridos en materia de Gobierno Abierto. España, ha presentado hasta la fecha tres Planes de Acción, encontrándose en fase de elaboración el cuarto de ellos. Si bien la vigencia de este Plan debería haber sido el período comprendido entre 2019-2021, la presencia prolongada de un Gobierno en funciones en el año 2019 junto con el ahora recién declarado estado de alarma, han dejado paralizada la aprobación de este IV Plan de Gobierno Abierto en nuestro país. De este modo, si consultamos el portal de transparencia estatal, ${ }^{25}$ nos indica que el IV Plan tiene previsto desarrollarse en el segundo semestre de 2020. No obstante, ante la situación actual no sería extraño que la mayor parte de compromisos en materias de transparencia, colaboración y participación hicieran referencia a esta crisis sanitaria. Sin embargo, todo apunta a que dentro de las prioridades del Ejecutivo previstas para los próximos meses no se encuentre la de elaboración y aprobación de este Plan.

Siguiendo con el ejemplo municipal de «Decide Madrid» se ve claramente cómo, desde la declaración del estado de alarma, que, entre otras medidas, ha supuesto la limitación de la circulación ciudadana, la plataforma ha centrado sus propuestas en ayudas e ideas útiles para hacer frente a la crisis sanitaria. Un ejemplo de las iniciativas con más éxito está siendo «Compartimos Barrio- Ecosistema de proximidad», cuyo objetivo es crear un

tión de la situación de crisis sanitaria ocasionada por el COVID-19. Por otro lado, la segunda prórroga de éste la encontramos en: Real Decreto 487/2020, de 10 de abril, por el que se prorroga el estado de alarma declarado por el Real Decreto 463/2020, de 14 de marzo, por el que se declara el estado de alarma para la gestión de la situación de crisis sanitaria ocasionada por el COVID-19. Ambos Reales Decretos fueron convenientemente autorizados por el Congreso de los Diputados, tal y como exige el art. $116 \mathrm{CE}$.

${ }^{24}$ Un análisis sobre las consecuencias para grupos vulnerables del Real Decreto 463/2020, de 14 de marzo, por el que se declara el estado de alarma para la gestión de la situación de crisis sanitaria ocasionada por el COVID-19, podemos encontrarla en: Presno Linera, Miguel Ángel. 2020. «Estado de alarma por coronavirus y protección jurídica de los grupos vulnerables», en El Cronista del Estado Social y Democrático de Derecho, núm. 86-87, págs. 54-65.

${ }_{25}$ El portal de transparencia estatal puede ser consultado en la web: (https://ransparencia.gob.es/transparencia/transparencia_Home/index.html) 
registro de asociaciones y de empresas que puedan abastecer a la población que por diversas razones no pueda salir a la calle o no pueda hacer frente por sí sola a la situación de confinamiento. En la misma línea, algunas de las propuestas ciudadanas en el municipio de Madrid que están siendo más votadas durante la crisis sanitaria son: la habilitación de hoteles para sanitarios con el objetivo de reducir riesgo de contagio a sus familiares o el apagado de las luces de escaparates y vallas publicitarias para así disminuir el gasto energético.

Por otra parte, si analizamos las iniciativas participativas a nivel mundial veremos que sigue un patrón parecido a lo visto para España. Ejemplo de ello, es la web de la Alianza para el Gobierno Abierto (OGP, por sus siglas en inglés) que ha centrado sus últimas campañas en plantear opciones que ayuden tanto a la mejora de la transparencia de las estadísticas sobre contagios como a la propuesta de iniciativas ciudadanas o de la propia administración pública que aumenten la seguridad y calidad de vida de la población ante esta crisis sanitaria. Entre los enfoques de Gobierno Abierto que plantea la OGP para todos los países se encuentra la necesidad de crear una web oficial del Gobierno que ofrezca información actualizada sobre el coronavirus, con datos y recomendaciones. Además, en países como Grecia, Italia, Bulgaria, Estados Unidos o Brasil, entre otros, se están creando redes de voluntarios para participar en labores tan necesarias como pueden ser la ayuda a personas mayores, la traducción de textos informativos sobre el coronavirus o la entrega de alimentos, entre otras tantas iniciativas.

\section{III.CONSIDERACIONES FINALES}

Desde hace casi una década se viene reclamando una mayor participación ciudadana en los asuntos públicos ya que, tal y como acertadamente señala Presno Linera, «en los últimos tiempos ha hecho fortuna, y no solo entre los movimientos sociales más críticos, la expresión «no nos representan», con la que se quiere denunciar la insuficiente respuesta que el sistema representativo está ofreciendo a las aspiraciones ciudadanas de alcanzar una sociedad democrática avanzada» $(2015,137)$.

No se trata de cambiar el modelo de democracia representativa actual, pero sí de revisar las reglas del juego del sistema constitucional en lo que a la participación se refiere, pues evidentemente nuestro ordenamiento constitucional data de finales de los años setenta del siglo XX, momento en el cual no existían la mayor parte de redes de información y comunicación de las que disponemos desde comienzos del XXI y, más concretamente, desde la generalización del uso de internet y redes sociales como herramientas principales de comunicación. Por todo ello, «es hora de enfocar los esfuerzos en sus manifestaciones, en sus estructuras, en sus procesos, que son los que están 
recibiendo la mayoría de las críticas por parte de una ciudadanía ávida de participar, pero con nuevas reglas y tiempos diferentes a los establecidos actualmente» (Calderón Avellaneda 2012, 55).

Se considera necesario un aumento de los mecanismos de democracia directa gracias a las oportunidades que brinda internet. En este sentido, es necesario recordar que los instrumentos de participación directa que prevé nuestro texto constitucional son insuficientes para atender las demandas de la sociedad. Por un lado, se ha hecho uso del referéndum consultivo en muy pocas ocasiones y la opción de iniciar un procedimiento legislativo a través de ILP se ha convertido en algo tedioso y poco fructífero en prácticamente su totalidad. La inadmisión a trámite de la Mesa del Congreso, la cantidad de firmas exigidas por la CE para avalar dicha iniciativa, así como el plazo de tiempo requerido, son aspectos que han llevado al desencanto en la promoción de este tipo de procedimientos.

La ciudadanía reclama una mayor participación en aquellos asuntos que les afectan e, igualmente, exige una comunicación bidireccional con los poderes públicos de forma constante y no sólo en período electoral.

La mayor parte de los inconvenientes históricos que imposibilitaban llevar a cabo un acercamiento al modelo de democracia directa pueden entenderse superados fácilmente gracias a las TIC y, en particular, gracias a la aparición y generalización de internet. De este modo, consultas no prescriptivas son fácilmente viables a través de iniciativas de Gobierno Abierto que instauren un foro de debate a través del cuál se conozcan los intereses y opiniones individuales sobre un determinado tema. La mayor parte de esta participación de carácter directo o deliberativo viene produciéndose en mayor medida en los ámbitos municipales, por ser la administración más cercana al ciudadano, pero ello no se opone a la idea de comenzar a introducir mecanismos de participación en otros niveles, como el autonómico o estatal. No obstante, no toda materia pública debe ser objeto de este tipo de iniciativas de participación directa, pues desvirtuaría el propio modelo de democracia representativa a la vez que podría provocar situaciones indeseadas. Por ello, es necesario dejar claro una serie de límites a esta participación, que en principio podrían coincidir con los propios límites impuestos para la presentación de una ILP.

Por otra parte, para hacer esto posible sería necesaria la configuración de un nuevo derecho fundamental: el derecho de acceso a internet. En este punto se hace necesario resaltar que la revolución tecnológica acontecida en las últimas décadas ha sido una cuestión innegable que ha cambiado de forma sustancial el comportamiento de la sociedad, así como la forma de comunicarnos entre nosotros. La CE de 1978 se fraguó en un momento histórico donde el uso de medios informáticos comenzaba a implantarse en despachos, oficinas y en la propia administración pública. No obstante, la llegada de 
internet, y más aún su generalización en todos los ámbitos de la vida de cualquier individuo, era algo inconcebible en aquellos años. Es por esta razón que la única referencia que tenemos en nuestro texto constitucional al respecto habla del concepto de «uso de la informática», pero no como un nuevo derecho digno de protección, sino como un uso que debe ser limitado con el objetivo de proteger otros derechos fundamentales como son el honor y la intimidad.

Por todo ello, el nuevo derecho constitucional de acceso a internet debe configurarse como un derecho fundamental que contribuya al desarrollo personal y social del individuo. Se pretende así que nuestra Carta Magna se actualice a la realidad social del siglo XXI, al igual que ya han hecho los reformados Estatutos de Autonomía incorporándolo como un principio rector.

De este modo, el derecho de acceso a internet se podría revisar y colocar en el art. 20.1.a) CE, en el que se reconoce y protege el derecho a la libertad de expresión y opinión mediante la palabra, el escrito o cualquier otro medio de reproducción, y en el art. 20.1.d) CE, en el que se incluiría una reserva legal para determinar el contenido del derecho de acceso a internet, siguiendo así las directrices marcadas por la ONU.

Sin embargo, estos cambios del art. 20 CE supondrían la puesta en marcha de un procedimiento de reforma agravada de la Constitución, por lo que, de llevarse a cabo, sería ideal que la misma se aprovechará no sólo para la modificación de este precepto sino para una revisión en profundidad de todo el texto. Mientras tanto, el TC debe ser quien se encargue de una interpretación amplia y actualizada de estos derechos.

Por su parte, el éxito de las iniciativas de participación ciudadana como «we the people» o «e-petitions», en Estados Unidos y Reino Unido respectivamente, deberían ser un referente para el resto de los países que forman parte de la Alianza para el Gobierno Abierto. En nuestro país, por ejemplo, no existe iniciativa homóloga a éstas y la única forma disponible para que la ciudadanía pueda llegar a incidir de forma directa en el poder legislativo es a través de la iniciativa legislativa popular o del derecho de petición consagrado en el art. 29 CE. Iniciativas como las analizadas en Estados Unidos o Reino Unido podrían ser perfectamente extrapoladas a nuestro ordenamiento jurídico con una simple reforma de la Ley Orgánica 4/2001, de 12 de noviembre, reguladora del Derecho de Petición, en la que se incluya la existencia de una web (dependiente del Gobierno) que canalice, mediante un procedimiento de recogida de firmas suficientes (apoyos), las peticiones ciudadanas que conllevaría, o bien, como mínimo la respuesta del Ejecutivo o, en caso de que el apoyo fuera mayor, el debate parlamentario.

Es evidente que, sin perder de vista la esencia de la consagrada democracia representativa en la que vivimos, también es imperante la necesidad de 
construir un modelo más actual que permita iniciativas y mecanismos facilitadores de una mayor participación ciudadana en la toma de decisiones públicas. Así pues, se puede afirmar claramente que la mayoría de las políticas públicas que se adoptan no coinciden en el tiempo con la duración de las legislaturas, sean del ámbito territorial que sean, de tal forma que, si bien el mandato representativo supone una cesión de poder por parte del pueblo a los representantes, existen, en más de una ocasión, determinadas cuestiones polémicas que suscitan grandes debates entre la opinión pública. Ante esta panorámica, se plantea, por tanto, la necesidad imperiosa de la existencia de una mayor periodicidad para la creación y evaluación de las políticas públicas. Con ello, se pretende contribuir al diseño y mejora de los servicios públicos, dando voz al ciudadano sobre aquello que le pueda afectar de forma directa o indirecta.

\section{BIBLIOGRAFÍA}

ABADÍA, Lorenzo. 2011 «Derechos políticos y sociedad de la información. Elementos para un desarrollo de la democracia participativa». Tesis Doctoral. Universidad de Zaragoza.

Agudo Zamora, Miguel y Montero Caro, María Dolores. 2010. «El Modelo constitucional español de gobierno local», en Gobierno y democracia local: La experiencia andaluza y andina. Dir. Por. Castillo Blanco, F., Coord. por. Quesada Lumbreras, J.E., y Ramallo López, F.E. Unión Iberoamericana de Municipalistas, Granada. págs. 83-104.

Alonso GaRCÍA, Nieves. 2018. «La integración de nuevas fórmulas de participación en la democracia representativa contemporánea». Tesis Doctoral. Universidad de León.

Arnstein, Sherry. 1969. A Ladder of Citizen Participation. JAIP, Volumen 35, Núm. 4.

Balaguer Callejón, Francisco; Cámara Villar, Gregorio, et ali. 2018. «Capítulo XX: Los derechos políticos: reunión, asociación, participación y petición», en Manual de Derecho Constitucional, Vol. II. Decimotercera edición, Tecnos, Madrid, pág. 293.

BIRKINSHAW, P., 2010. «Freedom of information and its impact in the United Kingdom», en Government Information Quarterly, Vol. 27, Issue 4, págs. 312-321.

Burguera Ameave, Leyre. 2015. «Europa como oportunidad de participación política: la Iniciativa Ciudadana Europea (ICE)», en El paradigma del Gobierno Abierto. Retos y oportunidades de la participación, transparencia y colaboración. Edit. Cotino Hueso, Lorenzo. Universidad Complutense de Madrid, Madrid, págs. 263-273.

CABedo Mallol, Vicente José. 2009. «La iniciativa legislativa popular en las Comunidades Autónomas. La necesaria reforma de su legislación», en Teoría y Realidad Constitucional, núm. 24, págs. 455-476. 
Calderón Avellaneda, César. 2012. Otro Gobierno, Algón Editores, Granada, pág. 55.

Castells, Manuel. 2012. Redes de indignación y esperanza. Alianza Editorial, Madrid.

CAStells, Manuel. 2006. La Sociedad Red. Alianza Editorial. Madrid.

Leston-BAndeIRA, C., y Thompson, L. 2018. Exploring parliament. Edit. Kettering: Oxford University Press. pág. 350.

Montero Caro, María Dolores. 2020. «El encaje constitucional del modelo de Open Government». Tesis doctoral. Universidad de Córdoba.

Mulà Arribas, Anna. 2018. "Análisis jurídico, antecedentes y consecuencias de la Sentencia 177/2016, del Tribunal Constitucional, sobre prohibición de las corridas de toros en Cataluña» en RDUNED: Revista de Derecho UNED, núm. 22, págs. 407-436.

Oвама, Barack. 2009. «Transparency and Open Government Memorandum for the heads of executive departments and agencies» en Federal Register, Núm. 74-15, págs. 4685-4686.

Pereira Menaut, Antonio Carlos. 2016. «Para entender el Brexit», en Diario La Ley, Núm. 8812.

PÉREZ AlBerdi, María Reyes, 2010. «Participación política y derecho fundamental. El artículo 23.1 de la Constitución Española». Tesis doctoral. Universidad de Huelva.

Presno Linera, Miguel Ángel. 2020. «Estado de alarma por coronavirus y protección jurídica de los grupos vulnerables», en El Cronista del Estado Social y Democrático de Derecho, núm. 86-87, págs. 54-65.

Presno Linera, Miguel Ángel. 2015. «Causas jurídico-constitucionales de la desafección ciudadana hacia el sistema representativo» en Problemas actuales de Derecho Constitucional en un Contexto de Crisis, Dir. Tur Ausina, R., Coord. por Sanjuán Andrés, F.J., y Calabuig Puig, M.A., Colección Estudios de Derecho Constitucional, Edit. Comares, págs. 137-162.

RELYEA, H.C., 2009. «Federal freedom of information policy: highlights of recent developments», en Government Information Quarterly, Vol. 26, Issue 2, págs. 314-320.

Rodríguez Vergara, Ángel. 2018. «Capítulo XX: Libertades Públicas (II): El Derecho de asociación, la libertad de partidos políticos y los derechos de participación», en Manual de Derecho Constitucional, Novena Edición, Tecnos, Madrid, pág. 552.

SARmiEnto, Daniel. 2016. «y después del Brexit... ¿Qué?», en El Cronista del Estado Social y Democrático de Derecho, Núm. 64, págs. 42-47.

Serrano Sanz, José María. 2016. «La economía y el Brexit», en El Cronista del Estado Social y Democrático de Derecho, Núm. 64, págs. 18-21.

VeSTRI, Gabriele. 2017. «La necesaria previsión de un referendo abrogatorio en el sistema constitucional español», en Revista de Derecho, núm. 48, Fundación Universidad del Norte, pág. 199. 


\title{
NUEVAS OPORTUNIDADES DE PARTICIPACIÓN EN EL MARCO DEL MODELO DE GOBIERNO ABIERTO $^{1}$
}

\section{New Participation Opportunities within the framework of the Open Government Model}

\author{
María Dolores Montero Caro \\ Profesora Doctora del Área de Derecho Constitucional \\ Universidad de Córdoba \\ d22mocam@uco.es \\ https://orcid.org/0000-0001-9033-620X \\ http://dx.doi.org/10.18543/ed-68(1)-2020pp425-447
}

\section{Copyright}

Estudios de Deusto es una revista de acceso abierto, lo que significa que es de libre acceso en su integridad. Se permite su lectura, la búsqueda, descarga, distribución y reutilización legal en cualquier tipo de soporte sólo para fines no comerciales, sin la previa autorización del editor o el autor, siempre que la obra original sea debidamente citada y cualquier cambio en el original esté claramente indicado

Estudios de Deusto is an Open Access journal which means that it is free for full access, reading, search, download, distribution, and lawful reuse in any medium only for non-commercial purposes, without prior permission from the Publisher or the author; provided the original work is properly cited and any changes to the original are clearly indicated. 